http://dx.doi.org/10.32929/2446-8355.2019v28n1p29-41

\title{
INTERFERÊNCIA DE PLANTAS DANINHAS EM PASTAGEM DE Urochloa brizantha cv. Marandu
}

Leandro Spíndola Pereira ${ }^{1}$, Adriano Jakelaitis ${ }^{2 *}$, Gustavo Silva de Oliveira ${ }^{1}$, Gustavo Dorneles de Sousa ${ }^{1}$, Jeovane Nascimento Silva ${ }^{3}$, Estevam Matheus Costa ${ }^{4}$

\footnotetext{
${ }^{1}$ Graduando em Agronomia, Instituto Federal de Educação, Ciência e Tecnologia Goiano (IF Goiano), Campus Rio Verde, GO.

${ }^{2}$ Docente, Programa de Pós-Graduação em Ciências Agrárias, IF Goiano, Campus Rio Verde, GO. *E-mail do autor correspondente: adriano.jakelaitis@ifgoiano.edu.br

${ }^{3}$ Doutorando, Programa de Pós-Graduação em Ciências Agrárias, IF Goiano, Campus Rio Verde, GO.

${ }^{4}$ Mestrando, Programa de Pós-Graduação em Ciências Agrárias, IF Goiano, Campus Rio Verde, GO.
}

Recebido: 22/10/2018; Aceito: 22/03/2018

RESUMO: A determinação dos períodos de interferência torna-se necessário para delinear medidas de manejo de plantas daninhas em pastagens, principalmente quando a comunidade infestante interfere na produção de forragem. Assim, objetivou-se determinar os períodos de interferência de plantas daninhas na implantação da pastagem de Urochloa brizantha e avaliar a capacidade de rebrota desta após o corte. Foram conduzidos dois ensaios relacionados aos períodos de convivência e de controle de plantas daninhas com a forrageira. No primeiro, os tratamentos consistiram em períodos de convivência a partir da emergência com períodos iniciais crescentes de 7, 14, 21, 28, 35, 42, 49, 56 e 66 dias após a emergência (DAE) de $U$. brizantha. As parcelas foram mantidas livres da convivência de plantas daninhas por capinas manuais semanais após cada período de convivência. No segundo, os tratamentos consistiram em períodos de controle, onde a forrageira foi mantida, a partir da emergência, sem a convivência com plantas daninhas pelos mesmos períodos, e aquelas que emergiram após não foram controladas até o corte da forrageira, aos 66 DAE. Nicandra physaloides foi a planta daninha de maior ocorrência na pastagem. Quanto maior foi o período de convivência das plantas daninhas com a forrageira maior foi a interferência daquelas sobre o perfilhamento e a produção de forragem, principalmente de folhas. O período crítico de interferência de plantas daninhas na pastagem situou-se dos 8 aos 34 DAE. Na rebrota da forrageira, a interferência de plantas daninhas afetou o perfilhamento, cobertura vegetal das parcelas e a produção de folhas da forrageira.

Palavras-chave: Competição. Comunidade infestante. Rendimento forrageiro.

\section{WEED INTERFERENCE IN PASTURE OF Urochloa brizantha cv. Marandu}

\begin{abstract}
The determination of the periods of interference is necessary to delineate measures of weed management in pastures, especially when the weed community interferes with the production of forage. The objective of this study was to determine the weed interference periods during the implantation of the Urochloa brizantha pasture and to evaluate the shoot regrowth capacity after cutting. Two trials were conducted related to weed coexistence and weed control. In the first trial, the treatments consisted of periods of
\end{abstract}


coexistence from the emergency and by increasing initial periods of 7, 14, 21, 28, 35, 42, 49, 56 and 66 days after emergence (DAE) of $U$. brizantha. The plots were kept free from the cohabitation of weeds by weekly manual weeding after each coexistence period. In the control experiment the forage was maintained from the emergency without the coexistence with weeds for the same periods, and those that emerged after they were not controlled until the forage cut, at 66 DAE. Nicandra physaloides was the most frequent weeds in the pasture. The longer the period of coexistence of weeds with the larger forage was the interference of these on tillering and forage production, mainly leaves. The critical period of weed interference in pasture is from 8 to $34 \mathrm{DAE}$. In forage regrowth, weed interference affected the tillering, vegetation cover of the plots and the production of forage leaves.

Key words: Competition. Weed community. Forage yield.

\section{INTRODUÇÃO}

A pecuária brasileira se caracteriza por elevada dependência de pastagens e aproximadamente $70 \%$ das áreas ocupadas com forrageiras encontram-se em estado de degradação (IBGE, 2016). Vários fatores são responsáveis por este cenário, como o manejo inadequado do solo e da forrageira, o uso de germoplasmas inadequados e, consequentemente, a ocupação do espaço por plantas daninhas (BUNGENSTAB, 2012).

As plantas daninhas competem diretamente com as forrageiras por luz, água e nutrientes, promovendo a redução da produção de forragem durante a fase de implantação do pasto, podendo inviabilizar a formação deste, onerando os custos operacionais e a sanidade do rebanho. O grau de interferência da comunidade infestante com as plantas cultivadas depende da população infestante caracterizado pela composição específica, densidade e distribuição das populações, das características da própria forrageira como espécie, espaçamento e densidade de semeadura, das condições de solo, clima e manejo e da época e duração do período de convivência mútua (SILVA et al., 2003; CAVALCANTE et al., 2017; OLIVEIRA, 2018).

Embora as espécies forrageiras, principalmente as do gênero Urochloa, se caracterizem por apresentar alta capacidade competitiva e alto rendimento forrageiro, porém, a falta de conhecimento no manejo cultural associado ao baixo nível tecnológico empregado, contribuem para que a interferência das plantas daninhas reduza o rendimento forrageiro em até 90\% (JAKELAITIS et al., 2010). Silva e Silva (2007) retratam a importância do conhecimento dos períodos de interferência e de controle de plantas daninhas nas culturas agrícolas para a definição de manejos racionais para combatê-las, no entanto, ainda há poucos estudos relacionados às plantas forrageiras, que mostrem as perdas ocasionadas pela interferência das plantas daninhas.

O período crítico de prevenção da interferência (PCPI) é o intervalo em que a espécie cultivada deve ser mantida sem a convivência de plantas daninhas para não ocorrer perdas significativas de rendimento da planta cultivada. Por outro lado, o período anterior à interferência (PAI) é definido a partir da semeadura ou emergência da planta cultivada em que ela pode conviver com as plantas daninhas, sem que ocorra perda expressiva de 
produtividade. Por outro lado, o período total de prevenção à interferência (PTPI) é o período a partir da semeadura ou emergência da cultura que ela deve ser mantida sem a convivência com plantas daninhas para que possa manifestar plenamente seu potencial produtivo. Assim, o PCPI é situado entre o limite superior do PAI até o PTPI (PITELLI, 2014; CORRÊA et al., 2016).

Diante do exposto, objetivou-se determinar os períodos de interferência de plantas daninhas na implantação da pastagem de Urochloa brizantha e avaliar a capacidade de rebrota desta após o corte.

\section{MATERIAL E MÉTODOS}

Dois ensaios foram instalados em 10 de dezembro de 2017 no campo experimental do Instituto Federal de Educação Ciência e Tecnologia Goiano (IF Goiano), Campus Rio Verde, GO, sob as coordenadas geográficas $17^{\circ} 48^{\prime} 28.2^{\prime \prime}$ Sul e 50 54' 09.9" Oeste e altitude de 720 metros. O clima da região é Aw mesotérmico, tropical de savana, pela classificação de Köppen, com chuva no verão e seca no inverno. A precipitação total $(1.155 \mathrm{~mm}) \mathrm{e}$ temperatura média durante a condução da pesquisa encontram-se na Figura 1.

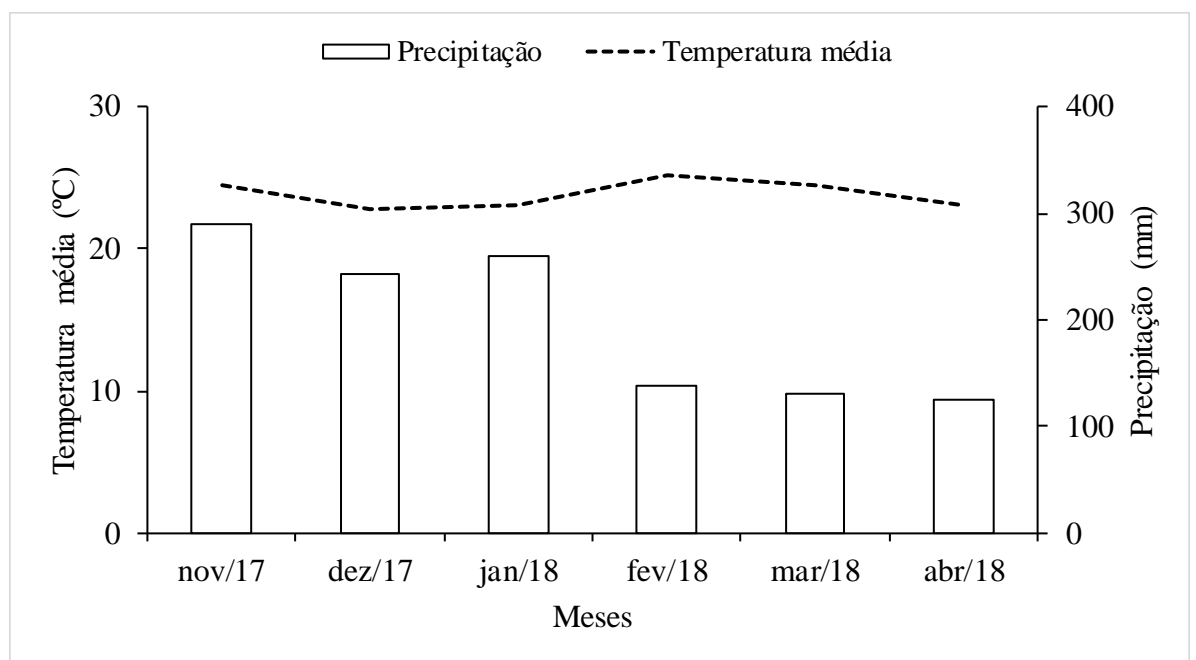

Figura 1. Temperatura média e precipitação durante o período experimental. Precipitation and average temperature) during the experimental period.

$\mathrm{O}$ solo do local foi analisado, na profundidade de 0 a $0,20 \mathrm{~m}$ apresentando: $\mathrm{pH}=6,2$ (SMP), $\mathrm{Ca}=4,64 \mathrm{cmol}_{\mathrm{c}} \mathrm{dm}^{-3}, \mathrm{Mg}=2,50 \mathrm{cmol}_{\mathrm{c}} \mathrm{dm}^{-3}, \mathrm{~K}=0,46 \mathrm{cmol}_{\mathrm{c}} \mathrm{dm}^{-3}, \mathrm{Al} 3+=0,04 \mathrm{cmol}_{\mathrm{c}}$ $\mathrm{dm}^{-3}, \mathrm{H}+\mathrm{Al}=4,5 \mathrm{cmol}_{\mathrm{c}} \mathrm{dm}^{-3}, \mathrm{CTC}=12,1 \mathrm{cmol}_{\mathrm{c}} \mathrm{dm}^{-3}$ e P $($ Melich $)=13,1 \mathrm{mg} \mathrm{dm}^{-3}, \mathrm{MO}=$ $3,62 \mathrm{mg} \mathrm{dm}^{-3}$ e $\mathrm{Zn}=4,5 \mathrm{mg} \mathrm{dm}^{-3}$, saturação por bases de $62,8 \%$, saturação por alumínio de $0,5 \%$, argila $=64,5 \%$, silte $=10,0 \%$ e areia $=25,5 \%$.

Antes da instalação dos ensaios a vegetação da área foi constituída por Alternanthera tenella (apaga-fogo), Commelina benghalensis (trapoeraba), Digitaria insularis (capimamargoso), Sida spp. (guanxuma) e Ipomoea spp (corda-de-viola), e foi dessecada quimicamente com glifosato na dose de $1.440 \mathrm{~g} \mathrm{ha}^{-1}$ do produto comercial na concentração de 480 g e.a. $\mathrm{L}^{-1}$. Quinze dias após a dessecação foi feito o preparo do solo por meio de aração e duas gradagens. A abertura dos sulcos no solo foi feita com cultivador e a semeadura manual 
foi realizada em linha, a uma profundidade de $0,02 \mathrm{~m}$, em espaçamento único de 0,5 metros. Foram utilizadas sementes certificadas e incrustadas de valor cultural de $80 \%$, adotando a recomendação de $5 \mathrm{~kg} \mathrm{ha}^{-1}$ de sementes puras viáveis. A adubação de semeadura foi de 150 $\mathrm{kg} \mathrm{ha}^{-1}$ do formulado 04-20-18 $\left(\mathrm{N}_{-} \mathrm{P}_{2} \mathrm{O}_{5}-\mathrm{K}_{2} \mathrm{O}\right)$ e em cobertura de $50 \mathrm{~kg} \mathrm{ha}^{-1}$ de nitrogênio, aplicados na forma de ureia aos 30 dias após emergência (DAE).

Foram conduzidos dois grupos de ensaios, caracterizados por períodos de convivência e períodos de controle de plantas daninhas com a espécie forrageira Urochloa brizantha cv. Marandu. O delineamento experimental utilizado foi o de blocos casualizados completos, com quatro repetições. Cada unidade experimental foi composta por 4 linhas de 2,5 $\mathrm{m}$ de comprimento. No ensaio de períodos de convivência, os tratamentos foram representados pela convivência da forrageira com as plantas daninhas desde a sua emergência até os períodos iniciais crescentes de 7, 14, 21, 28, 35, 42, 49, 56 até os 66 DAE da forrageira. As parcelas foram mantidas sem convivência de plantas daninhas por meio de capinas manuais semanais após cada período de convivência. Contrariamente, no ensaio períodos de controle, a forrageira foi mantida sem a convivência com plantas daninhas pelos mesmos períodos e aquelas que emergiram após os mesmos não foram controladas até o corte do capim, aos 66 DAE.

Dois cortes de uniformização foram realizados na forrageira, aos 66 e aos 106 DAE, correspondendo a 40 dias após o primeiro corte (DAC), com o auxílio de um cutelo a $0,15 \mathrm{~m}$ do solo. Após o primeiro corte, aos $66 \mathrm{DAE}$, quando foram determinados os períodos de interferência de plantas daninhas na implantação da pastagem, foi realizado a capina manual de todas unidades experimentais e avaliados os efeitos dos períodos de interferência na rebrota da forrageira.

Ao término de cada período de convivência, em ambos os ensaios, foi realizado o levantamento da comunidade infestante por meio do lançamento ao acaso de dois quadrados amostrais, vazados, de $0,16 \mathrm{~m}^{2}$ por parcela. As plantas daninhas foram coletadas e identificadas, separadas, acondicionadas em embalagens de papel e conduzidas à estufa de renovação e circulação forçada de ar a $65^{\circ} \mathrm{C}$ por 72 horas, até atingir massa constante, sendo posteriormente pesadas.

Aos 66 DAE e aos 40 DAC foi avaliada a produção de massa seca das forrageiras, sendo coletadas em 1,5 m nas duas linhas centrais de cada unidade experimental as plantas de $U$. brizantha. Após o corte foi realizado o peso da massa fresca da forragem e, posteriormente, foi retirado uma alíquota de aproximadamente $0,5 \mathrm{~kg}$ para determinação da massa seca. Destas amostras foram separados as folhas e os colmos. Em seguida, foram acondicionadas em embalagens de papel e levadas para secagem em estufa de renovação e circulação de ar forçada a $65^{\circ} \mathrm{C}$, por 72 horas, para posterior determinação das massas secas de folhas (MSF) e colmos (MSC).

Foi avaliada em ambas as épocas de colheita, a relação folha/colmo (RFC) calculada pela relação MSF por MSC. A altura do dossel (AD) da forrageira foi determinada antes de cada corte, com régua graduada em $\mathrm{cm}$, sendo aferida a altura em dois pontos aleatórios na parcela. A densidade de perfilho foi realizada lançando ao acaso dois quadrados amostrais, vazados de $0,25 \mathrm{~m}^{2}$, pela contagem do número de perfilhos (NP) situados nos quadrados. Aos 
40 DAC, avaliou-se a porcentagem de nota de cobertura (NC) das parcelas pela forrageira, atribuindo-se notas visuais entre zero e $100 \%$, sendo zero correspondente à parcela descoberta e 100\% à parcela totalmente coberta (RIZZARDI; FLECK, 2004) pela forrageira.

Os resultados obtidos foram submetidos a ANOVA $(\mathrm{p}<0,05)$ e quando demonstrado significâncias, procedeu-se a realização da análise de regressão $(\mathrm{p}<0,05)$. Na fase de implantação da pastagem para definição dos períodos de interferência (PAI, PTPI e PCPI) foi determinada a produção relativa de massa seca dos tratamentos em relação à testemunha, cultivada livre da convivência das plantas daninhas até os $66 \mathrm{DAE}$, e foi admitido 5\% de perdas aceitáveis no rendimento de forragem.

\section{RESULTADOS E DISCUSSÃO}

A comunidade de plantas daninhas nos ensaios foi composta por 17 espécies, distribuídas em 9 famílias. A família mais representativa foi a Poaceae com as espécies Zea mays (milho-tiguera), Cenchrus echinatus (capim-carrapicho), Digitaria horizontalis (capimcolchão), Digitaria insularis (capim-amargoso), Eleusine indica (capim-pé-de-galinha) e Urochloa plantaginea (capim-marmelada); seguida por Amaranthaceae: Alternanthera tenella (apaga-fogo), Amaranthus hybridus (caruru-roxo) e Amaranthus viridis (caruru-de-mancha); Euphorbiaceae: Euphorbia heterophylla (leiteiro) e Chamaesyce hirta (erva-de-santa-luzia); Malvaceae: Sida cordifolia (guanxuma) e Sida rhombifolia (guanxuma); Asteraceae: Acanthospermum hispidum (carrapicho-de-carneiro); Solanaceae: Nicandra physaloides (joáde-capote); Commelinaceae: Commelina benghalensis (trapoeraba) e Portulacaceae: Portulaca oleraceae (beldroega).

A planta daninha dominante nos ensaios foi $N$. physaloides, que representou 83 e $72 \%$, respectivamente, nos ensaios de períodos de convivência e de períodos de controle das plantas daninhas na pastagem. Em ensaios de matocompetição com espécies forrageiras que resultaram em perdas significativas do rendimento de forragem, as plantas daninhas foram diversificadas, uma vez que, cada região apresenta particularidades edáficas e climáticas, além das espécies que compõem a comunidade infestante. Mota (2017) avaliando a convivência de plantas daninhas com a forrageira Panicum maximum cv. Massai em Barra do Garça - MT, relatou que as espécies dominantes foram Waltheria americana (malva-veludo), Spermacoce latifolia (erva-quente) e Urena lobata (malva). Em Rolim de Moura - RO, Jakelaitis et al. (2010) encontraram maior ocorrência das espécies Triunfetta bartramia (carrapichão), Hyptis atrorubens (fazendeiro), D. horizontalis (capim-colchão) e A. hispidum (carrapicho-de-carneiro) em ensaios de matocompetição com U. brizantha.

Nas Figuras 2A e 2B são apresentadas, respectivamente, as densidades e as massas seca das plantas daninhas que ocorreram até os 66 DAE da pastagem em ambos os ensaios. De forma geral, observaram-se maiores densidades de plantas daninhas nas fases iniciais do ciclo da forrageira, com redução dos valores de forma mais acentuada no ensaio de períodos de controle, onde o crescimento da forrageira inibiu a infestação, pelo sombreamento e competição entre a forrageira e as plantas daninhas, principalmente por luminosidade, a partir dos 28 DAE. Para a densidade de plantas daninhas no ensaio de períodos de controle verificou-se maior densidade de indivíduos aos 14 DAE, com média de 86 indivíduos por m². 
Estes resultados assemelham-se aos reportados por Jakelaitis et al. (2010) que observaram em ensaios de períodos de controle de plantas daninhas a redução na densidade de indivíduos da comunidade infestante com $U$. brizantha a partir dos $35 \mathrm{DAE}$ da forrageira.

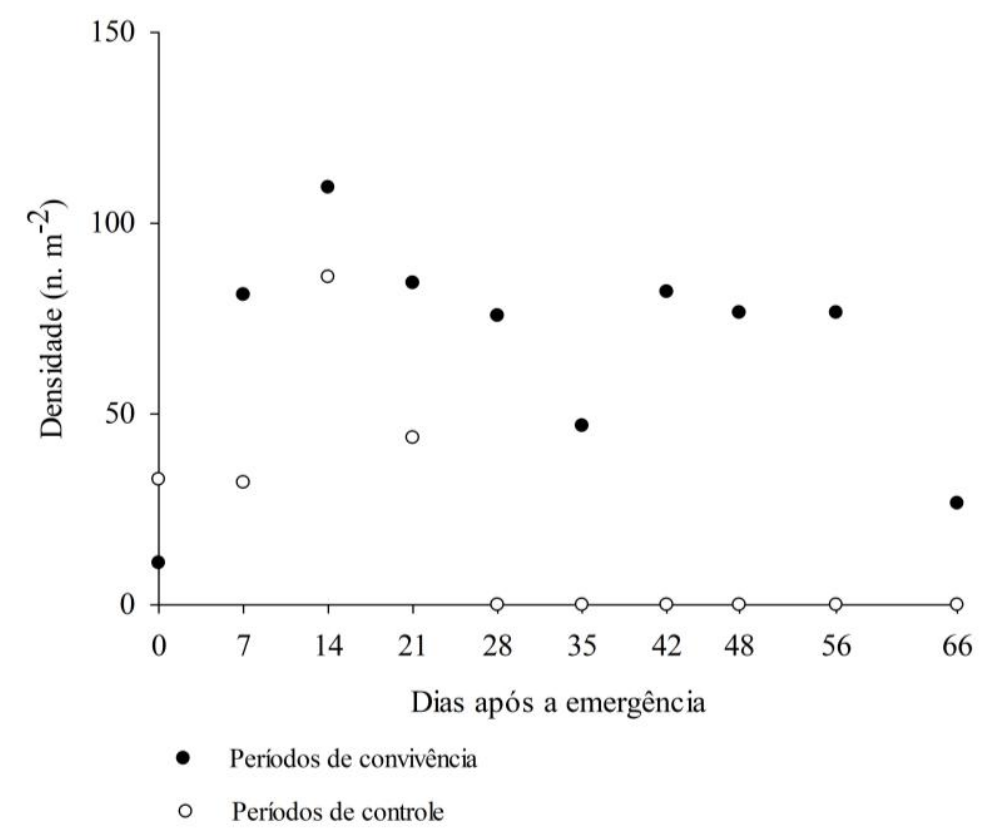

(A)

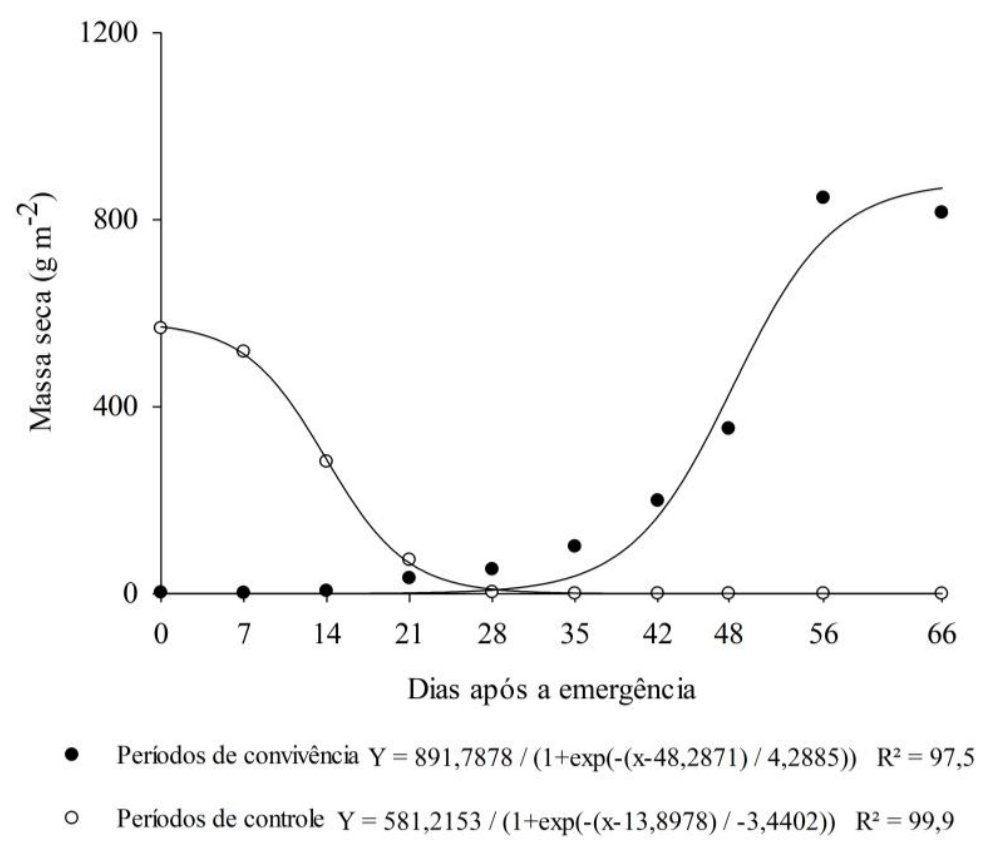

(B)

Figura 2. Densidade (A) e massa seca (B) de plantas daninhas em função dos períodos de convivência e de controle com a forrageira Urochloa brizantha cv. Marandu. Density (A) and dry mass $(B)$ of weeds according to the periods of coexistence and control with the forage Urochloa brizantha cv. Marandu.

Não foi possível explicar o comportamento da densidade de indivíduos em função dos períodos de controle ou de convivência pelo não ajuste de modelos de regressão, o que está relacionado com a aleatoriedade da infestação presente na área, podendo ser resultado do 
fluxo de emergência escalonada das sementes das plantas infestantes (Figuras 2A, B). Para a densidade de indivíduos verificou-se nos períodos de convivência que a população de plantas daninhas se situou entre 11 a 110 indivíduos por $\mathrm{m}^{2}$, com maior densidade aos 14 DAE da forrageira, e a infestação permaneceu alta até o corte da mesma aos 66 DAE, demonstrando a necessidade de controle de plantas daninhas nos períodos iniciais, logo após a emergência da forrageira.

Observou-se no ensaio de períodos de convivência que o aumento da massa seca da comunidade infestante iniciou-se aos 21 DAE e apresentou 50\% de resposta aos 48 DAE da forrageira, explicado pelo modelo logístico, indicando que as plantas daninhas apresentaram intenso crescimento vegetativo, a qual se estendeu até o corte da forrageira aos $66 \mathrm{DAE}$, com acúmulo máximo de $891 \mathrm{~g}$ de massa seca por $\mathrm{m}^{2}$ (Figura 2B). Por outro lado, no ensaio de períodos de controle, o decréscimo no acúmulo de massa seca da comunidade infestante atingiu 50\% da resposta aos 14 DAE e a manutenção do controle até os 21 DAE da $U$. brizantha suprimiu o acúmulo de massa seca das plantas daninhas. Durigan et al. (1983) ressaltam que o controle inicial reduz o acúmulo de massa seca de plantas daninhas na colheita da cultura, indicando que aquelas que emergem juntamente com cultura possuem maior capacidade competitiva, reduzindo a produção. Por outro lado, segundo os autores, as que emergem depois dos períodos de controle tem sua importância reduzida na competição com a espécie cultivada.

As plantas daninhas presentes nos ensaios de convivência e de controle com $U$. brizantha até os 66 DAE reduziram a MSF e a MSC da forrageira e não afetaram a AD, NP e a RFC (Tabela 1). A MSF e MSC ajustaram ao modelo linear, com redução de 14,19 e 17,62 $\mathrm{kg} \mathrm{ha}^{-1}$ por dia de convivência, respectivamente, resultando em perdas médias de 32\%, quando comparada à forrageira cultivada livre de interferência de plantas daninhas. Quando se faz o controle de plantas daninhas, os ganhos diários para as variáveis MSF e MSC são de 21,16 e 27,63 kg ha ${ }^{-1}$, respectivamente. Jakelaitis et al. (2010) avaliando o rendimento forrageiro de $U$. brizantha em função dos períodos de controle e de convivência de plantas daninhas observaram aos $63 \mathrm{DAE}$ da forrageira, ganhos e perdas, respectivamente do rendimento de forragem (caules + folhas), contudo explicados por modelos não lineares. Mota (2017) observou redução do rendimento forrageiro de Panicum maximum cv. Massai, ocasionada pela menor produção de folhas e de colmos da forrageira em convivência, que resultou na menor produção de matéria seca, matéria orgânica e proteína bruta dos tratamentos em convivência em grande parte do período após a emergência. 
Tabela 1. Altura do dossel (AD), número de perfilhos (NP), massas secas de folhas (MSF) e colmos (MSC) e relação folha colmo (RFC) de plantas de Urochloa brizantha cv. Marandu nos períodos de convivência e de controle de plantas daninhas no primeiro corte da forrageira aos 66 dias após a emergência - DAE. Canopy height (AD), number of tillers (NP), leaf dry masses (MSF) and stems (MSC) and leaf stem ratio (RFC) of Urochloa brizantha $\mathrm{cv}$. Marandu in the periods of coexistence and control with the weed community in the first cut of the forage at 66 days after the emergency $-D A E$

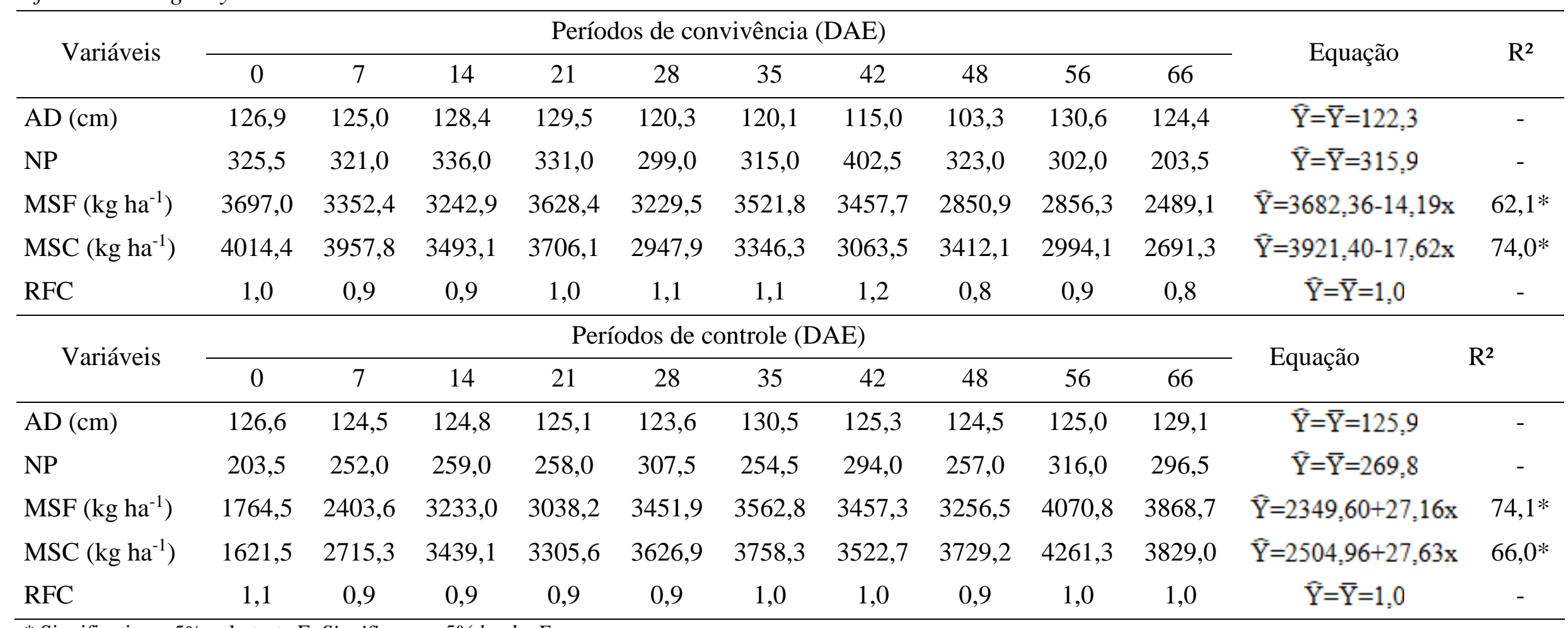

* Significativo a $5 \%$ pelo teste F. Significant at $5 \%$ by the F test. 


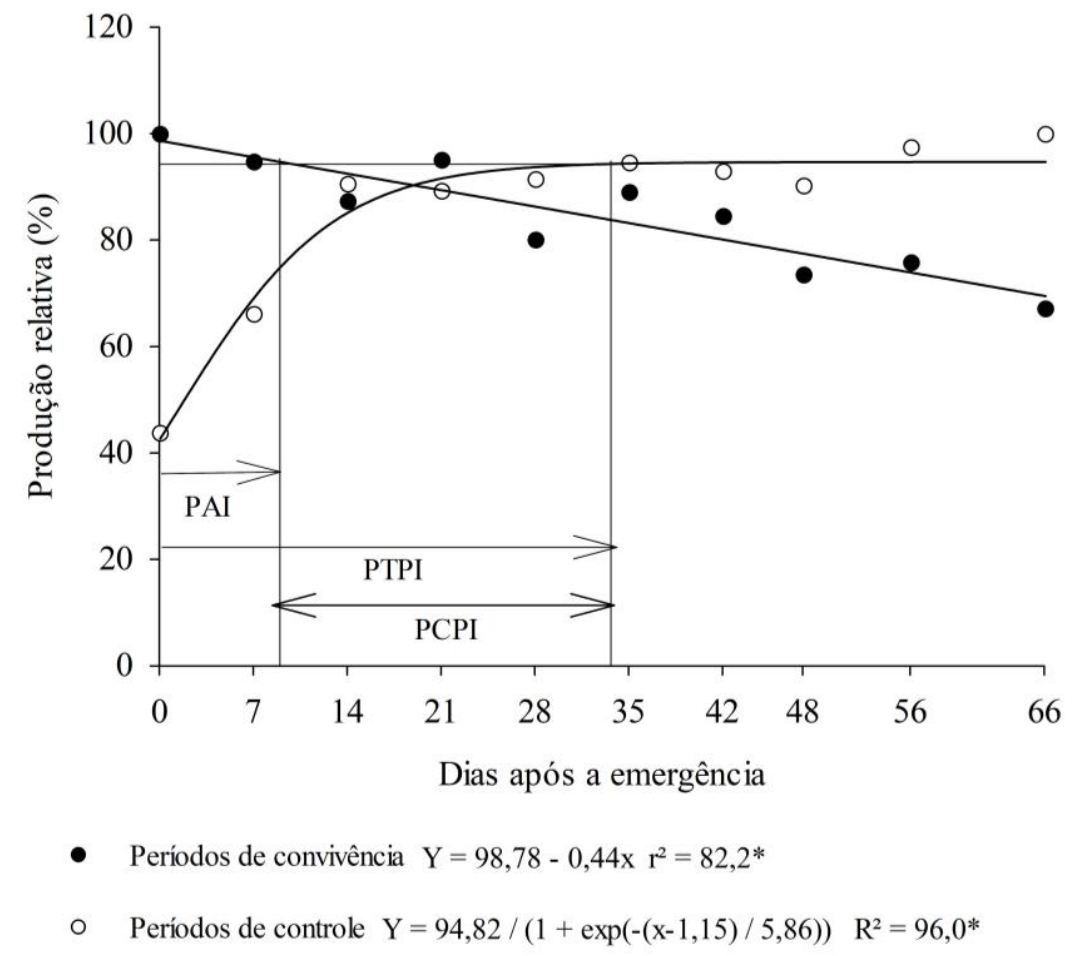

Figura 3. Produtividade relativa da forrageira Urochloa brizantha cv. Marandu em resposta aos períodos de convivência e de controle de plantas daninhas. Admitindo $5 \%$ de perdas o PAI foi de 8 dias, o PTPI de 34 dias e o PCPI entre 8 e 34 dias após a emergência da forrageira. Relative productivity of the forage Urochloa brizantha $\mathrm{cv}$. Marandu in response to the periods of coexistence and weed control. Admitting 5\% of losses the PAI was 8 days, the PTPI of 34 days and the PCPI between 8 and 34 days after emergence of the forage.

Na Figura 3 são apresentados os resultados da produção relativa (\%) considerando a massa seca total da forrageira calculada em relação aos tratamentos livres de interferência das plantas daninhas em ambos os ensaios até os 66 DAE. Observou-se que a forrageira conviveu com a comunidade infestante sem ter decréscimo significativo na sua produção relativa até os 8 DAE, caracterizando o período anterior à interferência (PAI). Após este período de competição já instalada, cada dia de convivência entre a comunidade infestante e a forrageira resultou em queda significativa da produção relativa de forragem. Assim, percebe-se que, no final do PAI encontra-se o momento apropriado para o controle das plantas daninhas que se encontram no início do seu desenvolvimento vegetativo, com alta infestação e baixo acúmulo de massa seca, onde as técnicas de controle empregadas são geralmente mais eficientes (Figuras 2 e 3).

O PTPI das plantas daninhas com a $U$. brizantha estendeu-se até os 34 DAE da forrageira, e após este período observou-se que a forrageira estabelecida promoveu, pelo sombreamento, o controle cultural, impedindo a germinação e o estabelecimento de plantas daninhas. Desta forma, o PCPI iniciou-se a partir do 8 DAE e se estendeu até os 34 DAE (Figura 3), corroborando com os reportados para Urochloa por Jakelaitis et al. (2010) com PCPI entre 9 e 26 DAE e Victoria Filho et al. (2002) dos 15 aos 45 DAE da forrageira. 
Tabela 2. Altura do dossel (AD), porcentagem de nota cobertura vegetal (NC), número de perfilhos (NP), massas secas de folhas (MSF) e colmos (MSC) e relação folha colmo (RFC) de plantas de Urochloa brizantha cv. Marandu nos períodos de convivência e de controle das plantas daninhas avaliados 40 dias após o corte da forrageira (rebrota). Canopy height (AD), percentage of vegetation cover (NC), number of tillers (NP), leaf dry masses (MSF) and stalks (MSC) and leaf stem ratio (RFC) of Urochloa brizantha plants cv. Marandu during the periods of coexistence and control of the weed community evaluated 40 days after forage cutting (regrowth)

\begin{tabular}{|c|c|c|c|c|c|c|c|c|c|c|c|c|}
\hline \multirow{2}{*}{ Variáveis } & \multicolumn{10}{|c|}{ Períodos de convivência (DAE) } & \multirow{2}{*}{ Equação } & \multirow{2}{*}{$\mathrm{R}^{2}$} \\
\hline & 0 & 7 & 14 & 21 & 28 & 35 & 42 & 48 & 56 & 66 & & \\
\hline $\mathrm{AD}(\mathrm{cm})$ & 98,6 & 97,8 & 100,4 & 98,5 & 98,3 & 100,9 & 102,1 & 104,8 & 103,8 & 84,5 & $\widehat{\mathrm{Y}}=\overline{\mathrm{Y}}=99,0$ & - \\
\hline NP & 448,5 & 488,0 & 416,0 & 509,5 & 505,0 & 421,5 & 474,0 & 477,5 & 347,5 & 237,8 & $\widehat{\mathrm{Y}}=430,35+5,739 \mathrm{x}+0,123 \mathrm{x}^{2}$ & $77,6^{*}$ \\
\hline $\operatorname{MSF}\left(\mathrm{kg} \mathrm{ha}^{-1}\right)$ & 2966,6 & 2780,0 & 3177,4 & 3160,8 & 2893,6 & 2862,7 & 2698,4 & 2850,0 & 2793,1 & 1867,2 & $\widehat{\mathrm{Y}}=2663,62+19,62 \mathrm{x}-0,477 \mathrm{x}^{2}$ & $74,7^{*}$ \\
\hline RFC & 1,5 & 1,5 & 1,7 & 1,7 & 1,4 & 1,5 & 1,2 & 1,1 & 1,4 & 1,4 & $\widehat{\mathrm{Y}}=\overline{\mathrm{Y}}=1,4$ & - \\
\hline \multirow{2}{*}{ Variáveis } & \multicolumn{10}{|c|}{ Períodos de controle (DAE) } & \multirow{2}{*}{ Equação } & \multirow{2}{*}{$\mathrm{R}^{2}$} \\
\hline & 0 & 7 & 14 & 21 & 28 & 35 & 42 & 48 & 56 & 66 & & \\
\hline $\mathrm{AD}(\mathrm{cm})$ & 71,6 & 76,3 & 74,3 & 79,3 & 80,5 & 79,6 & 78,8 & 78,8 & 91,0 & 80,6 & $\widehat{\mathrm{Y}}=\overline{\mathrm{Y}}=79,1$ & - \\
\hline $\mathrm{NC}(\%)$ & 52,8 & 67,5 & 62,5 & 71,0 & 75,8 & 79,5 & 86,3 & 87,5 & 93,8 & 96,8 & $\widehat{\mathrm{Y}}=57,07+0,64 \mathrm{x}$ & $95,6^{*}$ \\
\hline RFC & 2,0 & 2,1 & 2,2 & 2,3 & 2,1 & 2,1 & 2,1 & 2,1 & 1,9 & 2,0 & $\widehat{\mathrm{Y}}=\overline{\mathrm{Y}}=2,1$ & - \\
\hline
\end{tabular}

* Significativo a $5 \%$ pelo teste $\mathrm{F}$. Significant at $5 \%$ by the $\mathrm{F}$ test. 
Nos modelos estimados observaram-se para a convivência de plantas daninhas com a forrageira que a queda da produção foi linear de $0,44 \%$ por dia de convivência, o que promoveu 29\% de redução no rendimento forrageiro até os 66 DAE (Figura 3). Por outro lado, na ausência de um controle de plantas daninhas nas fases iniciais de estabelecimento da forrageira as perdas de rendimento podem atingir $56 \%$.

Após o primeiro corte da U. brizantha, aos 66 DAE, verificou-se que os efeitos da competição de plantas daninhas, tanto as estabelecidas no ensaio de convivência como de controle, reduziram a porcentagem de cobertura vegetal das parcelas (NC), o perfilhamento (NP) e a MSF avaliados aos 40 dias após o corte (DAC) (Tabela 2). Oriundos do ensaio de convivência, a MSF, o NP e a NC ajustaram-se a modelos quadráticos, com queda acentuada à medida que aumentaram os períodos de convivência durante a fase de implantação da pastagem com pontos de máximo de 24, 24 e 20 DAE, respectivamente.

Por outro lado, oriundo dos ensaios de controle, a queda nas variáveis NC e MSF ajustaram-se a modelos lineares, com acréscimos de 0,64\% e 15,69 $\mathrm{kg} \mathrm{ha}^{-1}$ para cada dia sem convivência das plantas daninhas durante a fase inicial da pastagem, enquanto o perfilhamento (NP) ajustou-se ao modelo quadrático com ponto de máximo valor aos 50 DAE. A AD, MSC e RFC não foram afetados pelos tratamentos.

Os efeitos significativos da interferência impostas na fase inicial do ciclo da forrageira foram manifestados na rebrota, indicando perdas na capacidade de perfilhamento, na cobertura do solo pela forrageira e no rendimento forrageiro de folhas, quando houve o prolongamento da convivência e redução no período de controle de plantas daninhas (Tabela 2). Jakelaitis et al. (2010) observaram que os efeitos dos períodos de controle iniciais de plantas daninhas durante a formação da pastagem de $U$. brizantha promoveram ganhos de $78,05 \mathrm{~kg} \mathrm{ha}^{-1} \mathrm{dia}^{-1}$ no rendimento forrageiro da rebrota, enquanto a convivência inicial da comunidade infestante na pastagem proporcionou redução de 66,64 $\mathrm{kg} \mathrm{ha}^{-1} \mathrm{dia}^{-1}$ no rendimento forrageiro, reforçando a necessidade de controle também na rebrota.

\section{CONCLUSÃO}

A interferência de plantas daninhas reduz o rendimento forrageiro de $U$. brizantha cv. Marandu na fase de implantação e na rebrota da pastagem, principalmente a produção de folhas.

O período anterior à interferência (PAI) foi até os 8 DAE, o período total de prevenção à interferência (PTPI) até os $34 \mathrm{DAE}$ e o período crítico de prevenção à interferência (PCPI) na implantação da pastagem situou-se entre 8 e 34 DAE.

\section{AGRADECIMENTOS}

Ao Instituto Federal de Educação, Ciência e Tecnologia Goiano, Campus Rio Verde e ao Conselho Nacional de Desenvolvimento Científico e Tecnológico (CNPq) pelo apoio financeiro. 


\section{REFERÊNCIAS BIBLIOGRÁFICAS / REFERENCES}

BUNGENSTAB, D. J. Sistemas de integração lavoura pecuária-floresta: a produção sustentável. 2. ed. Campo Grande: Embrapa Gado de Corte, 2012. 239 p.

CAVAlCANTE, J. T.; FERREIRA, P. V.; CUNHA, J. L. X. L.; SILVA JÚNIOR, A. B.; SILVA, M. T.; CARVALHO, I. D. E. Períodos de interferência de plantas daninhas em genótipos de batata-doce. Cultura Agronômica, Ilha Solteira, v. 26, n. 4, p.640-656, 2017. Disponível em: <http://as.feis.unesp.br/revcultagr/pages/edicao/44/sumario/401/view;jsessionid=9e65af71a2b 0ea94910a0de2a0cd>. Acesso em: 12 dez. 2018.

CORRÊA, M. J. P.; AlveS, G. L.; ROCHA, L. G. F.; SILVA, M. R. M. Períodos de interferência de plantas daninhas na cultura do feijão caupi. Revista de Ciências Agroambientais, Alta Floresta, v. 13, n. 2, p.50-56, 2016. Disponível em: <https://periodicos.unemat.br/index.php/rcaa/article/view/1183/1257>. Acesso em: 23 dez. 2018.

DURIGAN, J. C.; VICTORIA FILHO, R.; MATUO, T.; PITElli, R. P. Períodos de matocompetição na cultura da soja (Glycine max (L.) Merril), cultivares Santa Rosa E IAC-2. I- Efeitos sobre os parâmetros de produção. Planta Daninha, Viçosa, v. 1, n. 2, p.86-100, 1983. Disponível em <http://www.scielo.br/pdf/pd/v6n2/02.pdf>. Acesso em: 12 dez. 2018.

INSTITUTO BRASILEIRO DE GEOGRAFIA E ESTATÍSTICA - IBGE. Mudanças na cobertura e uso da terra 2000 - 2010 - 2012 - 2014. Rio de Janeiro: IBGE, 2016. 44 p. Disponível em <https://biblioteca.ibge.gov.br/visualizacao/livros/liv101469.pdf >. Acesso em: 10 nov. 2018.

JAKELAITIS, A.; DE OLIVEIRA GIL, J.; SIMÕES, L. P.; SOUZA, K. V.; LUDTKE, J. Efeitos da interferência de plantas daninhas na implantação de pastagem de Brachiaria brizantha. Revista Caatinga, Mossoró, v. 23, n. 1, p.8-14, 2010. Disponível em <https://periodicos.ufersa.edu.br/index.php/caatinga/article/view/1332/pdf>. Acesso em: 25 out. 2018.

MOTA, R. V. Produtividade do capim Massai sob interferência de plantas daninhas em área de renovação. 2017. 51 f. Dissertação (Mestrado em Agronomia - Produção Vegetal) Universidade Federal de Goiás, Jataí, 2017.

OLIVEIRA, F. das C. S. de. Interferência das plantas daninhas na produtividade e nutrição da cultura do milho verde em São Luís-MA. 2018. 56 f. Dissertação (Mestrado em Agronomia - Produção Vegetal) - Universidade Estadual Paulista, Jaboticabal, 2018.

PITELli, R. A. Competição entre plantas daninhas e plantas cultivadas. In: MONQUERO, P. A. Aspectos da biologia e manejo das plantas daninhas. São Carlos: Rima, 2014. cap. 3, p. 61-81.

RIZZARDI, M. A.; FLECK, N. G. Métodos de quantificação da cobertura foliar da infestação de plantas daninhas e da cultura da soja. Ciência Rural, Santa Maria, v. 34, n. 1; p.13-18, 
2004. Disponível em <http://www.scielo.br/pdf/cr/v34n1/a03v34n1>. Acesso em: 25 nov. 2018.

SILVA, A. G.; REZENDE, P. M.; GRIS, C. F.; GOMES, L. L.; BOTREL, E. P. Consórcio sorgo-soja. IX. Influência de sistemas de cortes na produção de forragens de sorgo e soja consorciados na linha e de sorgo em monocultivo. Ciência e Agrotecnologia, Lavras, v. 27, n. 2, p.451-461, 2003. Disponível em: <http://www.scielo.br/pdf/cagro/v27n2/a28v27n2.pdf〉. Acesso em: 15 dez. 2018.

SILVA, A. A.; SILVA, J. F. Tópicos em manejo de plantas daninhas. Viçosa: Editora UFV, 2007. 357 p.

VICTORIA FILHO, R.; CORSI, M.; BALSALOBRE, M. A. A.; SANTOS, P. M.; LADEIRA, A.; SVICERO, E. F. Período crítico de interferência de plantas daninhas na implantação de pastagem de Brachiaria brizantha. In: CONGRESSO BRASILEIRO DA CIÊNCIA DAS PLANTAS DANINHAS, 23, 2002, Gramado. Anais... Gramado: SBCPD, 2002. p. 94. 